\title{
DETERMINING OFFICIAL LANGUAGES IN THE FEDERAL STATES IN NEPAL
}

\author{
Dan Raj Regmi
}

While population is the major criterion for determining official languages, other criteria such as language vitality, identity, linguistic right, linguistic geography should be rationally evaluated along with population in terms of numeric rating scales. Exclusively based on merit list, official language should be recommended in the federal states in Nepal.

Keywords: official language, multilingualism, ethnic identity, linguistic right, rating scale, merit list

\section{Background}

This paper presents some elementary techniques for assessing the criteria for determining official languages other than Nepali in the federal states in Nepal and suggests some strategies for meeting the challenges to be faced in the implementation of those techniques in Nepal.

Prior to consolidation in the eighteenth century, local forms of speech were uninterruptedly recognized as official languages in the twenty-two and twenty-four petty states of Nepal. The foundation of linguistic pluralism deep-rooted in Nepal, in a planned way, began to be traumatized with the recognition of Gorkha Bhasa (Nepali) as the only official language of the consolidated Nepal. This plan of traumatization effectively prolonged in the Rana Period (1846-1950) was forcefully accelerated in the Panchayat Period (1960-1990). Language assimilation policy reverberated in "One nation, one language", founded in monolingual ideology, was uninterruptedly enjoyed by the state until the promulgation of the Constitution of Nepal in 1990. Nepali written in Devanagari script was declared as the language of the nation (i.e., official language) and all the forms of speech spoken as mother tongues as the national languages. Local Self Governance Act (2055 BS) authorized the local bodies to use local languages as official languages (Clauses 96 and 189).The endeavor of using Maithili and Newar in the local levels was crushed by the verdict of Supreme Court in 1999. However, the struggle continued in its pace and strength.

The interim constitution of 2007 declared all the languages spoken as mother tongues as languages of nation and granted right of the use of mother tongues as official languages in the local bodies and government offices. However, no crucial attempts were made for the implementation of such provision in practice. The constitution of Nepal, 2015 framed under the fundamental principles of socialism, federalism and inclusion has, knowingly or unknowingly, made some "tricky" of biased provision for the use of national languages in the federal states other than Nepali. Some discourses for looking for criteria for determining the official languages in the federal states has been duly initiated by Language Commission formed in 2016. However, such discourse for proposing criteria needs to be further widened and academically rectified.

This paper is organized into nine section sections. In Section 2, we briefly present the theoretical underpinning of the paper. Section 3 explains the need for determining the criteria for selecting official languages. In section 4, we briefly discuss the efforts for determining criteria. Section 5 looks at the criteria for determining official languages whereas in Section 6, we propose the model for evaluation of the criteria. In Section 7 , we discuss the major problems in implementing the criteria. Section 8 suggests some major strategies for solving the problems implementing the criteria. Section 9 concludes the paper.

\section{Theoretical underpinning}

Fairclough (1989:1) affirms that, in modern society, use of language may maintain and change power relations. Moreover, the power and ideology of the speakers of certain language determines the social and legal status of the language in concern. Selection of particular language/s as official language/s (i.e., language/s having specific legal status and used within 
government (viz., in courts, parliament, and administration) in the whole country or specific areas/federal states) may contribute to unequal relation of power. As per the constitutional criterion of 'majority', only a few languages are likely to be recommended for official languages in the specific provinces. Minority languages (indigenous as well as symbol of ethnic identity) will never be designated as official languages. Such situation will further contribute to the domination of minority speech communities by 'majority' speech communities as Fairclough pointed out. In order to help increase consciousness among the minority speech communities about the possibility for their languages to be official languages in the federal states, indigenous languages have to be recommended, on merit basis, for official languages. The majority 'ideology' at any cost should not be promoted despite the fact that present constitution has not set any further provisions except 'majority criterion'.

\section{Need for determining criteria}

The Constitution of Nepal, 2015 has recognized all languages spoken as the mother tongues as the languages of the nation (Article 6) and the Nepali language in the Devanagari script as official language of Nepal (Article 7 (1)). Article 7(2) has granted states the right, by framing a state law, to determine one or more than one languages of the nation spoken by a majority of people within the state as its official language(s), in addition to the Nepali language. Article 7(3), has authorized the Government of Nepal to decide other matters relating to language on recommendation of the Language Commission. Undoubtedly, "majority" is the foundation of democracy. However, with a view to including the minority speech communities by considering the complex ethnolinguistic architecture of Nepal, apart from the major criteria of "majority" other realistic and sensible criteria have to be sought after and national consensus has to be maintained as soon as possible. Nepal presents a threefold ethnic/religious-linguistic structure (Proposal of LinSuN, 2008:14). Nepali, official language, is spoken as mother tongue by $44.6 \%$, Maithili (11.7\%), Bhojpuri (6.0\%), Tharu (5.8\%), Tamang
(5.1\%), Newar (3.2\%), Bajjika (3.0\%), Magar (3.0\%), Doteli (3.0\%), and Urdu (2.6\%). Chhetri, the largest caste/ethnic group having $16.6 \%$ of the total population, is followed by Brahman-Hill (12.2\%), Magar (7.1\%), Tharu (6.6\%), Tamang (5.8\%), Newar (5.0\%), Kami (4.8\%), Musalman (4.4\%), Yadav (4.0\%) and Rai (2.3\%) (Central Bureau of Statistics, 2012). This situation presents a dire need of determining the other criteria in consonance with the ethno-linguistic situation of Nepal. Further, they have to be rationally synthesized.

\section{Efforts for determining criteria}

The Language Commission conducted workshops and seminars participated by concerned stakeholders, speech communities and experts in different provinces and centers to determine the criteria as per its five year roadmap. The Commission has collected a number of suggestions for setting up the criteria for determining official languages in the federal states in Nepal. Some suggestions have also been collected while conducting sociolinguistic survey of some languages and dialects spoken in Nepal with the financial support of the Language Commission.

It is not an easy task to propose undisputed criteria for determining for determining official languages in the federal states in Nepal. However, six basic criteria, for the first time, were proposed in (Bandhu et al., 2017). They include population, multilingualism and identity, accessibility and language right, writing system and languages only in spoken form, availability of literature and use of the language in communication. Moreover, Bandhu et al. (2017) has strongly noted that the "Majority" criterion is not justifiable to the minority speech communities of Nepal. It has further strongly suggested that the basic criteria should be systematically synthesized. Bandhu et al. (2017) was immediately followed by YonjanTamang (2017). The latter has proposed five criteria for determining the official languages in the federal states of Nepal. They include population, linguistic geography (continuity of habitation), local identity and historicity of language, socio-cultural identity, language vitality 
and power. It is to be noted here that there are fundamental similarities between these two proposals. However, the former has laid primary emphasis on the spirit of multilingualism and identity whereas the latter has prioritized the number of speakers. Whatever criteria are proposed, they are virtually rooted on the national context and international practices exercised mainly in India, Pakistan, China, Russia, Papua New Guinea, Latvia, USA(Hawaii).

In India, Hindi (written in Devanagari script) spoken by 14.5 to $24.5 \%$ as mother tongue, people have accepted it as the official language considering the principles of majority, identity and national integrity. Besides Hindi, English is also acknowledged as the official language mainly on the principle of national integrity. In Pakistan, $7.59 \%$ speak Urdu as mother tongue and Urdu has got the status of official language on the principles of national identity and language of wider communication rather than majority criterion. China has accepted 'Standard Chinese', one of the dialects of Mandarin Chinese, as the official language of the country.

Russia, a multilingual country, has recognized only Russian as the official language at central level. However, in the provincial level, 35 mother tongues including Russian have been approved as official languages. In Papua New Guinea, more than 850 languages are spoken. However, only four languages, viz. Tok Pisin, Hiri Motu, English and the Sign language are recognized as official languages. In Latvia, Latvian is the official language constitutionally. A noteworthy matter in Latvia is that Russian spoken by around onefourth of the population has been deliberately categorized as a foreign language. In the USA, languages spoken by minorities on the principle of inclusion have been recognized as the official languages in the state level. In Hawaii, English and Hawaiian are the official languages, whereas in Alaska, around twenty mother tongues including English have been approved as official languages.

Regmi (2017b) has extended the criteria for determining the official languages proposed in Bandhu et al. (2017) and briefly evaluated each basic criterion in terms of numeric rating scales. It has proposed for making a merit list of all the languages before recommending for the official languages in federal states. In Nepal, indeed, majority, identity, national integrity, language of extensive communication, policy of inclusion may, broadly, be the major criteria for determining the official languages at the provincial levels.

\section{Criteria for determining official languages}

It is not an easy task to maintain unanimous consensus in setting criteria for determining official languages in the federal states in Nepal. However, consensus has to be sought after following discussions and interactions among stakeholders, speech communities and language experts. The criteria so far to be proposed are naturally liable to be revised as far as further ethno-linguistic information is made available. Some criteria may be proposed on the basis of international practices, interactions and seminars. They are briefly discussed as follows:

\section{a. Number of speakers}

A language or languages spoken by a specified percentage at the provincial or local level may be taken as one of the criteria for determining the official status of the language(s) in Nepal. However, such criterion may not justifiable as there has not yet been conducted a reliable census of the languages in Nepal (Regmi, 2018). Thus, other criteria such as multilingualism and identity have to be considered along with the criterion of number of speakers.

\section{b. Language vitality}

Normally, a language or languages which is/are spoken in all most domains of language use by all age groups and learnt as the first language/s should be chosen as official language/s at the local or provincial levels. Endangered, shifting, severely endangered languages should not be prioritized at any pretence.

\section{c. Ethno-linguistic identity}

In the present context of Nepal, language is a symbol of ethnic identity. Thus, while choosing a language or languages for official purpose, historicity and social-cultural identity have to be considered as basic criteria. 


\section{d. Accessibility and linguistic right}

In consonance with the principle of multilingualism, the minority languages have to be prescribed for official use for providing the equal access to the government services and facilities.

\section{e. Language of wider communication}

A language or languages functioning as linguafranca in the provincial levels has/have to be recommended for official language/s.

\section{f. Linguistic geography}

A language spoken in densely populated communities has to be recommended as official language at the provincial levels.

\section{g. Linguistic originality (origin of language)}

For promoting the national integrity, languages originated or evolved in the native land have to be recommended. Such languages may be useful tools for transmitting the life-crucial knowledge and strengthening the national identity.

h. Development of writing system

The official language is mostly used in documenting official records in written form. Thus, languages without written tradition should not be preferably recommended for such purpose.

\section{i. Linguistic material development}

Normally standardized form of a language is used in government offices. Thus, the languages that have standard grammars, dictionaries and textbooks are the right candidates for the recommendation for official language.

\section{j. Corpus development}

Standard grammars, dictionaries and textbooks can be easily prepared for the languages with available corpus. Therefore, the languages that have already developed corpora should be prioritized for official use.

k. Availability of literature
Literature makes a language rich. A language with a rich literature may be easily and effectively used in different levels of education in the country. Thus, availability of literature should also be considered as the basic criterion for recommending a language for official language in the federal states in Nepal.

\section{Evaluation of the criteria}

In Section 4, eleven criteria have been proposed for determining official languages in the federal states in Nepal. These criteria have to be systematically synthesized for the proper implementation. However, such a task is not easy for mainly two reasons. First, all criteria are not equally important in the context of Nepal. Second, undisputable model for evaluating criteria is not available in the literature. One of the models of practical rating scale is numeric rating scale. It is a very difficult task to synthesize all the criteria so far proposed in Section 4.

Table 1: Evaluating the basic criteria in terms of numeric rating scales

\begin{tabular}{|l|l|l|l|l|l|}
\hline \multirow{2}{*}{ Major criteria } & \multicolumn{5}{|c|}{ Numeric rating scale } \\
\hline & 1 & 2 & 3 & 4 & 5 \\
\hline Population and & & & & $\mathrm{x}$ & \\
\hline Language vitality & & & $\mathrm{x}$ & & \\
\hline Ethno-linguistic identity & & & & & $\mathrm{x}$ \\
\hline $\begin{array}{l}\text { Accessibility material } \\
\text { linguistic right }\end{array}$ & & & & & $\mathrm{x}$ \\
\hline Linguistic geography & & $\mathrm{x}$ & & & \\
\hline Linguistic originality & & & $\mathrm{x}$ & & \\
\hline $\begin{array}{l}\text { Development of writing } \\
\text { system }\end{array}$ & & & & $\mathrm{x}$ & \\
\hline $\begin{array}{l}\text { Linguistic } \\
\text { development }\end{array}$ & & & $\mathrm{x}$ & & \\
\hline Corpus development & & $\mathrm{x}$ & & & \\
\hline Availability of literature & & & \\
\hline
\end{tabular}

$[1=$ poor, $2=$ fair, $3=$ good, $4=$ very good and $5=$ excellent]

It is to be noted that all criteria are not equally important in the context of Nepal and they have to be synthesized by using a practical rating scale. As per this rating scale, each criteria may be 
evaluated in terms of five rating scales (viz., $1=$ poor, $2=$ fair, $3=$ good, $4=$ very good and $5=$ excellent). Table 1 presents a model of evaluating the basic criteria in terms of numeric rating scales.

Table 1 indicates that a language $(\mathrm{X})$ proved to be excellent in all basic criteria in terms of numeric rating scales may be awarded 50 marks at the maximum. Thus, 50 may be supposed to be the full marks in the evaluation. However, in Nepal, a language (X) may be awarded 35 at the maximum. In Nepal, linguistic right of the minority speech communities has to be ensured in the spirit of multilingualism. Besides, migration rate has to be maintained as minimum as possible to encourage unified settlement in Nepal. Recognizing ethnolinguistic identity is also very important factor. As we have a number of crossborder languages such as Maithili, Bajjika, Bhojpuri, Awadhi, Rajbansi and Tibetan, linguistic originality has also been considered in Nepal. Development of writing system is awarded only three as there are a number of pre-literate languages in Nepal.

Table 2: Basis of evaluation of criteria

\begin{tabular}{|l|l|l|}
\hline Major criteria & $\begin{array}{l}\text { Rating } \\
\text { scale }\end{array}$ & Basis for evaluation \\
\hline Population & 4 & $\begin{array}{l}\text { To ensure linguistic right } \\
\text { to minority speech } \\
\text { communities }\end{array}$ \\
\hline Language vitality & 3 & $\begin{array}{l}\text { To encourage endangered } \\
\text { and shifting languages }\end{array}$ \\
\hline $\begin{array}{l}\text { Ethno-linguistic } \\
\text { identity }\end{array}$ & 5 & $\begin{array}{l}\text { To recognize } \\
\text { ethnolinguistic identity }\end{array}$ \\
\hline $\begin{array}{l}\text { Accessibility and } \\
\text { linguistic right }\end{array}$ & 5 & $\begin{array}{l}\text { To ensure linguistic right } \\
\text { in the spirit of } \\
\text { multilingualism }\end{array}$ \\
\hline $\begin{array}{l}\text { Linguistic } \\
\text { geography }\end{array}$ & 2 & $\begin{array}{l}\text { To encourage unified } \\
\text { settlement }\end{array}$ \\
\hline $\begin{array}{l}\text { Linguistic } \\
\text { originality }\end{array}$ & 3 & $\begin{array}{l}\text { Existence of cross-border } \\
\text { languages }\end{array}$ \\
\hline $\begin{array}{l}\text { Development of } \\
\text { writing system }\end{array}$ & 3 & $\begin{array}{l}\text { Prevalence of pre-literate } \\
\text { languages }\end{array}$ \\
\hline $\begin{array}{l}\text { Linguistic } \\
\text { material } \\
\text { development }\end{array}$ & 4 & $\begin{array}{l}\text { Prevalence of a little } \\
\text { linguistic materials }\end{array}$ \\
\hline $\begin{array}{l}\text { Corpus } \\
\text { development }\end{array}$ & 2 & $\begin{array}{l}\text { Prevalence of a little } \\
\text { corpus development }\end{array}$ \\
\hline $\begin{array}{l}\text { Availability of } \\
\text { literature }\end{array}$ & 3 & $\begin{array}{l}\text { Prevalence } \\
\text { unavailability of literature }\end{array}$ \\
\hline
\end{tabular}

Table 2 presents rating scale of each basic criterion along with the rationality behind the particular rating.

It is to be noted that the bases of the evaluation of basic criteria are rooted on the present ethnolinguistic complexity of Nepal, situation of language vitality, statistics of speakers of languages and their distribution, issues of ethnolinguistic identity and principle of inclusion.

Based on the numeric rating scales given in Table 1 , each language spoken in the areas where provincial and local levels are located has to be evaluated in overall. Each basic criterion, in turn, has to be turned into five rating scales. A language $(\mathrm{X})$ may be awarded five marks at the maximum provided it is spoken by $5 \%$ or above. Likewise, a language spoken by more than $4 \%$ and spoken by less than $5 \%$ may be awarded 4 marks at the maximum. Similarly, a language spoken by more than $3 \%$ and spoken by less than $4 \%$ may get only 3 marks.

In this model, some marks have to be awarded to a language spoken by less than $1 \%$. Table 3 presents a model for evaluating the number of speakers on the basis of numeric rating scale.

Table 3: Model for evaluating the number of speakers on the basis of numeric rating scale

\begin{tabular}{|l|l|l|l|l|l|}
\hline Basis for evaluation & \multicolumn{5}{|l|}{ Numeric rating } \\
& \multicolumn{3}{|c|}{ scale } \\
\hline & 1 & 2 & 3 & 4 & 5 \\
\hline $\begin{array}{l}\text { The language spoken by 5\% or } \\
\text { above }\end{array}$ & & & & & $\mathrm{x}$ \\
\hline $\begin{array}{l}\text { Language spoken by more than } \\
4 \% \text { and spoken by less than 5\% }\end{array}$ & & & & $\mathrm{x}$ & \\
\hline $\begin{array}{l}\text { Language spoken by more than } \\
3 \% \text { and spoken by less than 4\% }\end{array}$ & & & $\mathrm{x}$ & & \\
\hline $\begin{array}{l}\text { Language spoken by more than } \\
2 \% \text { and spoken by less than 3\% }\end{array}$ & & $\mathrm{x}$ & & & \\
\hline $\begin{array}{l}\text { Language spoken by more than } \\
1 \% \text { and spoken by less than 2\% }\end{array}$ & $\mathrm{x}$ & & & & \\
\hline
\end{tabular}

Likewise, while evaluating the criteria of language vitality, a vigorous language may be awarded five marks and a critically endangered 1 mark only. ${ }^{\mathrm{i}}$ Table 4 presents a model for evaluating language vitality on the basis of numeric rating scale. 
Table 4: Model for evaluating language vitality on the basis of numeric rating scale

\begin{tabular}{|l|l|l|l|l|l|}
\hline \multirow{2}{*}{ Basis for evaluation } & \multicolumn{5}{|c|}{ Numeric rating scale } \\
\cline { 2 - 7 } & 1 & 2 & 3 & 4 & 5 \\
\hline Vigorous & & & & & $\mathrm{x}$ \\
\hline Endangered & & & & $\mathrm{x}$ & \\
\hline Shifting & & & $\mathrm{x}$ & & \\
\hline Severely endangered & & $\mathrm{x}$ & & & \\
\hline Critically endangered & $\mathrm{x}$ & & & & \\
\hline
\end{tabular}

Similarly, in the evaluation of ethno-linguistic identity, one ethnic group-one language will be awarded five marks whereas the speech community in which language of wider communication is used more than the mother tongue will receive only one mark. Table 5 presents a model for evaluating ethno-linguistic identity on the basis of numeric rating scale.

Table 5: Model for evaluating ethno-linguistic identity on the basis of numeric rating scale

\begin{tabular}{|l|l|l|l|l|l|}
\hline Basis for evaluation & \multicolumn{5}{|c|}{ Numeric rating scale } \\
\cline { 2 - 7 } & 1 & 2 & 3 & 4 & 5 \\
\hline $\begin{array}{l}\text { one ethnic group one } \\
\text { language }\end{array}$ & & & & & $\mathrm{x}$ \\
\hline $\begin{array}{l}\text { one ethnic group but more } \\
\text { than one dialect }\end{array}$ & & & & $\mathrm{x}$ & \\
\hline $\begin{array}{l}\text { one ethnic group but more } \\
\text { than one language }\end{array}$ & & & $\mathrm{x}$ & & \\
\hline $\begin{array}{l}\text { ethnic group using mother } \\
\text { tongue and LWC equally }\end{array}$ & & $\mathrm{x}$ & & & \\
\hline $\begin{array}{l}\text { ethnic group using LWC } \\
\text { more than mother tongue }\end{array}$ & $\mathrm{x}$ & & & & \\
\hline
\end{tabular}

In this way, all the basic criteria have to be systematically evaluated. We have to prepare a merit list of all the languages spoken in the areas located local and provincial levels. We have to follow the following procedure for preparing merit list.

A language (X) spoken by more than $5 \%$ or above may obtain five marks in maximum. In the context of Nepal, as given in Table 1, language X can obtain only four marks. Thus, language $\mathrm{X}$ is awarded only four marks in the final evaluation. Similarly, language $\mathrm{X}$ obtained four marks in the evaluation of language vitality as being endangered. However, as given in Table 1, the maximum marks to language vitality have been conferred only three marks. Thus, at the end, language X can obtain only 2.4 marks.

The formula may be written as follows:

Marks obtained (4)

$\overline{\text { Max. Marks (5) }} \quad$ X Max. marks for LV (3) $=2.4$

In this way, we have to prepare a merit list on the basis of the grand total obtained by $\mathrm{X}, \mathrm{Y}, \mathrm{Z}$ languages spoken in the federal states of Nepal. The languages falling in merit lists should not be recommended for official languages. The languages that do not qualify for the eligibility of official status need to be strengthened so that they can compete next time. This process should be continued.

7 Major problems in implementing the criteria

Nepal requires to assuring the linguistic rights of the speech communities in consonance with the spirit of multilingualism. Thus, the criteria for choosing the official languages have to be decided on the basis of reliable and full information about the languages of Nepal. Such decision should be rooted on the principles of inclusion and ethnolinguistic reality of Nepal in order to enable the people to rightly use their linguistic rights. Speech communities in Nepal have not yet been made conscious about the interrelationship between the language, culture and society. The numbers of languages, their speakers as well as the distribution enumerated in different censuses of Nepal have not been fully reliable. The study of languages in Nepal is in its infancy. The studies done so far have to be corroborated with present situation of languages in Nepal. The major problems are briefly discussed as follows:

a. Lack of the language census

Till today, there has not been conducted scientific census of the languages of Nepal. Thus, Nepal lacks reliable and undisputed statistics as to the number of languages, their distribution and speakers. Languages counted by enumerators with limited knowledge of language situation of Nepal 
and limited number of questions in 2011 Census have number of problems (Regmi, 2018).

There is no uniformity in the number of languages enumerated in the six censuses carried out between $1992 / 54$ to 2011 . In 1952/54 census, 52 languages were enumerated as the mother tongues of Nepal. In the following three censuses, viz. 1961 (36), 1971(17), 1981(18) and 1991 (31) the number of languages is haphazardly and unreliably enumerated disgracing the dignity of speech communities of Nepal. After the reinstatement of democracy, in two censuses, viz., 2001(92) and 2011(123), the number of languages has increased. Heritage languages of ancestors or language of ethnic identity has been enumerated as mother tongues even though informants do not speak except Nepali.

Many international languages including English, French, and Spanish have been enumerated as mother tongues of Nepal. Some languages have been enumerated as two different languages. There are a number of inconsistencies as to the distribution of the speakers of the languages. Around 24 languages belonging to Rai-Kirati group have been enumerated as independent languages. At the same time, Rai with more than fifteen thousand speakers is again separately enumerated.

In reality, the speakers of Nepali as the first language are gradually increasing as many speech communities are shifting to Nepali. However, 2011 Census unreliably records $44.6 \%$ of population being the speakers of Nepali as mother tongue in Nepal. Thus, it would be quite impossible to ensure linguistic rights of the speech communities considering the number of speakers as the major criterion for determining official languages in Nepal.

b. Lack of a detailed study of vitality of
language

Based on the Expanded Graded Intergenerational Disruption Scale model proposed by Lewis and Simons (2010) Regmi (2013; 2017a) has made a preliminary assessment of the vitality of the languages enumerated in 2011 Census. ${ }^{i}$ This assessment reveals that only less than 44\% (53) languages are vigorous /safe. More than $41 \%$ (51) languages are threatened, i.e., only child bearing generations are transmitting these languages to their children. Likewise, $8.9 \%$ (11) languages are shifting and $4.87 \%$ (6) are moribund. Similarly, $0.8 \%$ (1) is nearly extinct and $0.8 \%$ (1) dormant. Generally, more than $56 \%$ of the languages are facing different levels of language endangerment in Nepal. As per the criteria proposed by Lewis and Simons (2010), a language used orally by all generations and being learnt by children as their first language is considered as the vigorous language. Vulnerable/threatened (i.e., languages used orally by all generations but only some of the child bearing generations are transmitting it to their children) and definitely endangered/shifting (i.e., the child-bearing generation knows the language well enough to use it among themselves but none are transmitting it to their children) have to be promoted as vigorous languages if they are to be recommended as official languages in federal states in Nepal. Similarly, unless severely endangered/moribund (i.e., the only remaining active speakers of the language are members of the grandparent generation) and critically endangered/nearly extinct (i.e., the only remaining speakers of the language are members of the grandparent generation or older who have little opportunity to use the language) are revitalized and upgraded to the vigorous level, they may not be practically prescribed for the official languages. A detailed vitality study is also required for eliminating the inconsistencies occurred in the census of the languages.

c. Lack of dissemination of the sociolinguistic situation of the languages

Linguistic Survey of Nepal (2009-2017) has already revealed the sociolinguistic situations of around 96 languages/dialects of Nepal. However, they have not yet been properly disseminated among the speech communities. Without the proper knowledge of the domains of language use, multilingualism, dialectal variations, language attitude, language resources and aspirations of the speech communities for the development of their language, no effective planning may be prepared to work with the spirit of multilingualism in Nepal. Such planning should give emphasis to the use of indigenous languages in different domains of language use. 
d. Lack of the study of accessibility of the speech communities

2011 Census provides some preliminary information as to the accessibility of different castes/ ethnicities on the principle of inclusion. However, there has not been yet conducted the survey of accessibility of the facilities of linguistic communities in Nepal. Besides, there is a lack of proper information on ethnicity/caste and language in Nepal. According to 2011 Census, around 10 castes ( Kshetry, Bramins ( Hills), Kami, Thakuri, Sarki, Sanyasi, Gaine, Badi, Khawas, Damai/Dholi) speak Nepali as the common mother tongue whereas 53 ethnicities have their different mother tongues. Thus, the survey of the accessibility of different castes/ ethnicities cannot provide a clear picture of the accessibility of the peoples and linguistic rights.

\section{e. Lack of writing system}

Only a few languages of Nepal have a tradition of writing. Such languages include Nepali, Maithili, Tibeti/Sherpa, Tamang, Newar, Limbu, Bhojpuri, Awadhi and Lepcha. Many languages of Nepal are preliterate. Normally, there is a tradition of selecting languages with established writing traditions. Generally languages in which grammars, dictionaries as well as textbooks have been made available are recommended for official status. Thus, it would be practically very difficult to select preliterate languages for such purposes. However, a preliterate local language may have to be recommended for official use.

\section{f. Lack of linguistic research}

Only a few languages of Nepal have been studied comprehensively. Such languages may include Nepali, Newar, Tamang, Maithili, Bhojpuri, Awadhi, Limbu, Bantawa, Koyee, Dumi, Bhujel, Sunar, Thami, Magar Kaike, Dolkha Newar, Kham, Darai, Hayu, Belhare, Athpahare, Chamling, Yakkha, Kusunda, Raji, Bajhangi, Achhami, Dadeldhuri, Rajbansi and Chepang. Many languages are still looking forward to be comprehensively studied.

g. Lack of consciousness about the importance of mother tongue
Michael Krauss (2002), a linguist, rightly remarks that any language is a supreme achievement of a uniquely human collective genius. He further points out that any language is divine and endless a mystery as a living organism. By far the most important remarks he has made is that language death matters, i.e., "the extinction of any animal species diminishes our world, so does the extinction of any language." Nelson Mandela, a political leader, once upholding the significance of mother tongue remarked that the address made in mother tongue only can touch the heart of addressee. He notes "If you talk to a man in a language (i.e., other than mother tongue), that goes to his head. If you talk to him in his language (i.e., mother tongue), that goes to his heart." For the great dramatist of Nepal, Balakrishna Sama, any language is civilization, and the symbol of every progress, i.e., language makes immortal every victory and every success. Due to the lack of education and knowledge about the importance of language, the attitude towards the mother tongue among the speech communities has not yet been effectively promoted as expected.

\section{Major strategies}

Determining criteria for the official languages in Nepal has been a very complex task. Unless short term and long term language planning with specific strategies is framed for the preservation, promotion and development of the languages of Nepal, no criteria would bear the expected result. There are some specific strategies to solve the problems in the implementation of the criteria. They are as follows:

a. If criterion of majority of speakers stated in the constitution is admitted, a systematic and scientific census of languages should be immediately conducted. Uncertainty about the number of languages, their speakers as well as the places of the speech community can be eliminated.

b. The vitality of the languages of Nepal has to be assessed following the model for vitality assessment referred to as Expanded Graded Intergenerational Disruption Scale expanded and revised by Lewis and Simons in 2010. 
c. Ethno-linguistic survey has to be immediately conducted for the ethno-linguistic identity of the speech communities in Nepal.

d. Language documentation programs have to be immediately framed and executed for strengthening the seriously endangered languages and assuring the accessibility of such speech communities in the services and facilities provided by the governments.

e. There should be the survey of accessibility of the facilities of linguistic communities in Nepal.

f. The major findings of the sociolinguistic survey of the languages of Nepal as to the domains of language use of all languages and dialects, situation of multilingualism, dialectal variations, language attitudes, language resources and aspiration of the speech communities for language development have to be duly considered while making any crucial decision about languages of Nepal.

g. An action plan for the writing of unwritten languages has to be immediately prepared and executed with the active participation of the speech communities and linguists.

h. Research of languages with active participation of speech communities has to be carried out.

i. Awareness program in the speech communities has to be framed and executed effectively and immediately.

\section{Summary and conclusion}

The Language Commission is assigned a special task to determine the criteria of selecting one or more languages as official languages in the federal states in Nepal. Some preliminary discussions have been made among stakeholders, speech communities, linguists and concerned authorities as to such criteria. However, right now, it is not easy to set "unanimously agreed criteria" in consideration to the language composition, federal structure and ethnolinguistic complexity in Nepal. Internationally, some criteria such as population, multilingualism, language of wider communication, national identity and national integrity have been in practice for assigning the role of official language. Till the date, identity and multilingualism and population are the competing criteria. However, in the present context of Nepal, all the major criteria have to be evaluated by applying the numeric rating scale. The marks obtained in individual criteria have to be re-evaluated. On the basis of the grand total of the marks, a merit list has to be prepared of the languages of each state. Language Commission is advised to recommend the government to assign the role of official language on the basis of the merit. No doubt, setting criteria has been a complicated task thanks to the lack of reliable number of speakers, lack of writing system and lack of the study of the languages of Nepal. Such hitches can be mitigated by framing an effective language planning immediately. Besides, census of languages and assessment of the vitality of all the languages of Nepal have to be immediately carried on. Recommending deserving languages by setting reliable and effective criteria to be the official languages in the federal states is the dire need of today's Nepal.

\section{References}

Bandhu, Churamani; Dan Raj Regmi and Prem Phyak. 2017. Sarakari kamkajko bhasa nirdharanaka adharharu (Criteria for determining official languages). A paper presented at the symposium on Constitutional Responsibility of Language Commission and its Future Roadmap organized by Language Commission, July 12, 2017, Kathmandu.

Central Bureau of Statistics. 2001. Population Census, Kathmandu: National Planning Commission.

Central Bureau of Statistics. 2012. National Population and Housing Census 2011: National Report. Kathmandu: National Planning Commission.

Fairclough, Norman. 1989. Language and Power. New York: Longman.

Government of Nepal. 2015. The constitution of Nepal. Kathmandu: Ministry of Law, Justice, and Parliamentary Affairs.

Lewis, M. P. and G. F. Simons. 2010. Assessing Endangerment: Expanding Fishman's GIDS. Revue Romaine de Linguistique 55.103-120.

Linguistic Survey of Nepal. 2008. Proposal of Linguistic Survey of Nepal. National Planning Commission, Nepal.

Regmi, Dan Raj. 2013. Nepalka Bhasaharuko Sarvekshan: Sthiti ra Chunauti (Linguistic 
survey of the languages of Nepal: Situation and challenges). A paper presented at the national workshop on the development of language policy in Nepal organized jointly by Ministry of Education and Nepal Academy, July 10, 2013, Kathmandu.

Regmi, Dan Raj. 2017a. Convalescing the endangered languages in Nepal: Policy, practice and challenges, Gipan, Vol.3.1, January, 2017.

Regmi, Dan Raj. 2017b. bhasa chanotka jatilata (Complexity in selecting languages). Kantipur Daily. 2 September, 2017 (Bhadra 17, 2074).

Regmi, Dan Raj. 2018. tapainle bolne dosro bhasa kun? (What language do you speak as the second language?). Kantipur Daily, 29 August, 2018 (Bhadra 13, 2075).

Yadava, Yogendra P. 2013. Linguistic context and language endangerment in Nepal. Nepalese Linguistics, Vol.28, 260-272.

Yadava, Yogendra. 2015. Language use in Nepal. Population Monograph of Nepal. Vol. II (Social Demography). p. 51-64.

Yonjan-Tamang, Amrit. 2017. Sarakari kamkajko bhasa nirdharana (Determining official languages). A paper presented at the interaction program on Language Policy in the Constitution of Nepal and Way forward organized by National Foundations for Development of Indigenous Nationalities, August 2, 2017, Lalitpur.

\footnotetext{
${ }^{\mathrm{i}}$ See section 6(b) for the definitions of different levels of language vitality.

ii See Yadava (2013) and (2015) for Linguistic context and language endangerment in Nepal language use in Nepal, respectively.
} 